\title{
Tracheostomy, ventilatory wean, and decannulation in COVID-19 patients
}

\author{
Chrysostomos Tornari ${ }^{1}$ (D) Pavol Surda ${ }^{1}$ (D) Arunjit Takhar ${ }^{1} \cdot$ Nikul Amin $^{1} \cdot$ Alison Dinham $^{2} \cdot$ Rachel Harding $^{2}$. \\ David A. Ranford ${ }^{1}$. Sally K. Archer ${ }^{3}$. Duncan Wyncoll ${ }^{4}$. Stephen Tricklebank ${ }^{4} \cdot$ Imran Ahmad ${ }^{5} \cdot$ Ricard Simo $^{1}$. \\ Asit Arora ${ }^{1}$
}

Received: 28 May 2020 / Accepted: 3 July 2020 / Published online: 1 August 2020

(c) Springer-Verlag GmbH Germany, part of Springer Nature 2020

\begin{abstract}
Purpose COVID-19 patients requiring mechanical ventilation can overwhelm existing bed capacity. We aimed to better understand the factors that influence the trajectory of tracheostomy care in this population to facilitate capacity planning and improve outcomes.

Methods We conducted an observational cohort study of patients in a high-volume centre in the worst-affected region of the UK including all patients that underwent tracheostomy for COVID-19 pneumonitis ventilatory wean from 1st March 2020 to 10th May 2020. The primary outcome was time from insertion to decannulation. The analysis utilised Cox regression to account for patients that are still progressing through their tracheostomy pathway.

Results At the point of analysis, a median 21 days (IQR 15-28) post-tracheostomy and 39 days (IQR 32-45) post-intubation, $35 / 69(57.4 \%)$ patients had been decannulated a median of 17 days (IQR 12-20.5) post-insertion. The overall median age was 55 (IQR 48-61) with a male-to-female ratio of 2:1. In Cox regression analysis, $\mathrm{FiO}_{2}$ at tracheostomy $\geq 0.4(\mathrm{HR} 1.80 ; 95 \% \mathrm{CI}$ $0.89-3.60 ; p=0.048$ ) and last pre-tracheostomy peak cough flow (HR 2.27; 95\% CI 1.78-4.45; $p=0.001$ ) were independent variables associated with prolonged time to decannulation.

Conclusion Higher $\mathrm{FiO}_{2}$ at tracheostomy and higher pre-tracheostomy peak cough flow are associated with increased delay in COVID-19 tracheostomy patient decannulation. These finding comprise the most comprehensive report of COVID-19 tracheostomy decannulation to date and will assist service planning for future peaks of this pandemic.
\end{abstract}

Keywords Tracheostomy $\cdot$ Tracheotomy $\cdot$ Decannulation $\cdot$ COVID-19 $\cdot$ SARS-CoV-2 $\cdot$ Peak cough flow

\section{Introduction}

\section{Background: the COVID-19 crisis}

COVID-19 results in critical illness for approximately $5 \%$ of infected patients [1]. A significant proportion require intensive care unit (ICU) admission where prolonged mechanical ventilation (MV) is likely [2, 3]. As a result, ICU capacity has had to more than double and this has significant implications for patient care $[4,5]$. Coupled with early learning from high-volume centres, measures are required to optimise ICU admission duration [6, 7]. Tracheostomy care and decannulation are of paramount importance in this regard. Therefore, close multidisciplinary working between ICU, nursing, physiotherapy, speech and language therapy (SLT), and ORL-HNS specialists would benefit from COVID19 -specific evidence to optimise this process. 


\section{Tracheostomy decision-making in COVID-19}

Tracheostomy is an established therapy with recognised benefit when performed early (within 7 days of MV). This includes a lower incidence of ventilator acquired pneumonia, reduced mortality, duration of MV, ICU stay, sedation, and laryngotracheal stenosis in survivors [8-10]. Evidence of benefit arises from clinical research prior to the COVID-19 pandemic when tracheostomy timing and technique (percutaneous vs open) were the main areas of debate.

The focus has changed dramatically in the COVID-19 era. Tracheostomy is an aerosol generating procedure which theoretically increases the risk of viral transmission to healthcare workers (HCWs), particularly during the early disease course $[11,12]$. Despite evidence that prolonged endotracheal intubation causes increased mortality and ventilatory weaning failure, some authors recommend tracheostomy only in exceptional circumstances [11,13]. Most guidelines favour later tracheostomy to mitigate $\mathrm{HCW}$ risk and allow time for patient prognosis to become clear to avoid futile procedures [14-16].

\section{Tracheostomy care and decannulation}

Access to specialist nursing, physiotherapy, and SLT can be limited outside of the ICU in some centres [17]. Therefore, prolonged tracheostomy duration could delay patient stepdown from critical care. Furthermore, changes to post-insertion tracheostomy care have been recommended to minimise HCW transmission of COVID-19 [15, 18]. These may limit rehabilitation and detailed patient assessment (e.g., nasolaryngoscopy) with, ultimately, delayed weaning [18, 19].

The decannulation process is complex and relies on the co-ordination of pharyngolaryngeal sensation, airway protection, and strength amongst other factors. Systematic reviews consistently identify clinical stability, neurological factors, secretion management, effective swallowing, strength of cough, and airway patency as important factors [20-22]. However, there are no robust prognostic factors and clinical guidelines are heavily based on expert opinion [20]. Finally, decannulation studies have heterogeneous casemixes with the limited studies available on primary respiratory failure highlighting this indication for tracheostomy as a negative prognostic factor of tracheostomy duration [22].

\section{COVID-19-specific modifications to medical care and early tracheostomy outcomes}

A number of measures have been proposed to prevent viral transmission and improve the treatment of COVID-19 based on the existing literature. One of these measures is the use of corticosteroids to treat a severe, hyperinflammatory state that is associated with a cytokine 'storm', though this treatment is of uncertain value [23-25].

There are only five reports of early outcomes of COVID19 tracheostomy [26-30] and none of these include a detailed analysis of the decannulation process. Given our experience as a High-Consequence Infectious Diseases tertiary referral centre in a region of the UK with more COVID-19-related critical care admissions than any other [31], we sought to evaluate our current outcomes. Furthermore, we aimed to identify relevant factors that affect decannulation to support the decision-making of colleagues tasked with managing COVID-19 tracheostomy patients in areas that are earlier in their first or subsequent pandemic peak.

\section{Materials and methods}

We included all patients that underwent tracheostomy [16] for COVID-19 pneumonitis respiratory wean from 1st March 2020 to 10th May 2020. Patients were excluded if it was not possible to obtain outcome data post-transfer to other hospitals; their primary tracheostomy indication was not prolonged MV; their electronic record was inaccessible; and if they died prior to sedation weaning. For included patients, data were collected for all time-points of interest unless unavailable (e.g., due to transfer to another hospital or department) and the number of patients that reached each time point (with or without available data) is documented in the results section.

Our standard management is to use a Tracoe Twist Plus cuffed, non-fenestrated tracheostomy tube with a subglottic suction port. We use a size $8+$ to $9+$ for most men, size $7+$ to $8+$ for most women, and Passy Muir ${ }^{\circledR}$ speaking valves. Patients were weaned from tracheostomy in a nonprotocol-driven (i.e., individualised) fashion by our highly specialist SLT and physiotherapy team with care to ensure MDT agreement regarding readiness for decannulation. In our institutions, due to the risk of aerosol generation, cuff deflation in COVID-19 patients does not commence until MV has ceased. We do not routinely cap tracheostomy tubes prior to decannulation. To commence weaning, patients had to be self-ventilating; cuff down trials were then initiated and airway patency was assessed with digital occlusion. If appropriate, a one-way valve was then trialled. To proceed with decannulation, patients had to tolerate $24 \mathrm{~h}$ with their cuff deflated and $12 \mathrm{~h}$ with a one way valve, have minimal/ no tracheal suctioning requirements and ideally be able to independently cough secretions to their mouth without any evidence of upper airway obstruction, bronchopulmonary infection, or high oxygen requirements [32]. All patients with suspected hyperinflammatory COVID-19 underwent joint evaluation with our lung inflammation service for 
consideration of immunomodulation therapy with methylprednisolone [33].

Data was collected and anonymised from electronic records as part of an audit registered within our institution. The primary endpoint was time from tracheostomy to decannulation. The following were recorded: demographics (age, body mass index [BMI], gender \& ethnicity); medical factors (very severe comorbidities, Acute Physiology And Chronic Health Evaluation II [APACHE II] score); ventilatory parameters at tracheostomy (positive end-expiratory pressure [PEEP], arterial oxygen pressure $\left[\mathrm{PaO}_{2}\right]$, fraction of inspired oxygen $\left[\mathrm{FiO}_{2}\right.$ ] [also collected at decannulation] $\& \mathrm{PaO}_{2}: \mathrm{FiO}_{2}$ ratio); and medical interventions (methylprednisolone use, vasopressor use, renal replacement therapy [RRT], anti-muscarinic medications, extracorporeal membrane oxygenation [ECMO] and proning) [31]. Relevant time-points were recorded including time from tracheostomy to weaning off sedation, ventilator weaning (liberation), first cuff down trial, ICU discharge, and decannulation. Measures of predictive factors in weaning were: Richmond agitation-sedation scale (RASS, a measure of neurological status with 0 being normal) on sedation wean; mobility (as a proxy measure of myopathy) on sedation wean; peak cough flow [PCF, recorded as a negative value pre-tracheostomy but presented as positive integers for clarity and comparability] immediately before and after tracheostomy; secretion burden at first cuff down trial; upper airway patency at first cuff down trial; swallow adequacy at first cuff down trial; and voice quality at first cuff down trial [20-22].

Secretion burden is defined on a scale [34] from no secretions through to copious secretions and documented in the IntelliSpace Critical Care and Anaesthesia software used in our institution (Release F.01.00, Philips, Amsterdam, The Netherlands). Swallow adequacy was the subjective binary outcome of the first bedside clinical swallowing assessment at the first cuff down trial by SLT. Voice quality was assessed by the subjective first assessment after the first cuff down trial by SLT, and was rated as aphonic, dysphonic, or normal.

This study was completed in accordance with the ethical regulations of our institutional audit approval body (registration number 10811) and national regulations of clinical audit against agreed standards [21].

\section{Statistical analysis}

\section{Univariate analysis of factors associated with late decannulation}

Based on a median decannulation time of 17 days for 35 patients that had been decannulated two groups were defined:
- Group I (early): decannulation was achieved $<17$ days after tracheostomy and

- Group II (late): decannulation was achieved $\geq 17$ days after tracheostomy including patients not yet decannulated beyond 17 days at the time of reporting.

Patients $<17$ days from tracheostomy were excluded from this univariate analysis. Depending upon the normality and nature of data, $p$ values were calculated using the Chi square test, Fisher's exact test, or the Mann-Whitney $U$ test. All tests were two-tailed.

\section{Multivariate analysis by Cox regression}

Starting with the most significant variable in the univariate analysis, backward stepwise log-likelihood ratio was used to determine whether inclusion of a new variable improved the fit of the Cox regression multiple model. Hazard ratios (HRs) were calculated from the regression model. Missing values were processed by missing value analysis followed by a multiple imputation model for outcome variables. Results were considered statistically significant where $p<0.05$. All calculations were made with standard commercial software (SPSS v 20.0, IBM Cord., Armonk, NY, USA).

\section{Results}

312 patients were admitted for critical care during the study period, of which 266 (85.3\%) were intubated. Seventy-eight $(29.3 \%)$ of the intubated patients underwent tracheostomy (73 Percutaneous [93.6\%], 3 Hybrid [3.85\%], and 2 Open [2.6\%]) of which $69(88.5 \%)$ were included. Four patients (5.1\%) died before sedation weaning as a result of their COVID-19 and five further patients met exclusion criteria (see Methods). Median follow-up was 21 days (interquartile range [IQR] 15-28) from tracheostomy corresponding to a median of 39 days (IQR 32-45) from intubation. The median primary endpoint of tracheostomy duration was 17 days (IQR 12-20.5) (Fig. 1). The number of patients that reached pertinent decannulation-related events (e.g., sedation cessation and cuff down trials) is presented in Fig. 1.

\section{Patient demographic metrics}

Baseline characteristics, medical parameters, relevant timepoints, and tracheostomy-relevant factors are presented in Table 1. COVID-19-specific markers of severe disease were the use of methylprednisolone in $35(50.7 \%)$ patients for a median 13 (IQR 9.5-16.0) days and prone positioning of 33 (47.8\%) patients for a median of 4 (IQR 2-5) days (Table 1). 
Fig. 1 Boxplot representing landmarks in tracheostomy care. The boxes represent interquartile ranges with thick lines representing medians. Whiskers represent the lowest and highest observations $\leq 1.5$ times the inter-quartile range from the box and orange dots (outside boxes) represent outliers. Purple dots (inside boxes) represent means

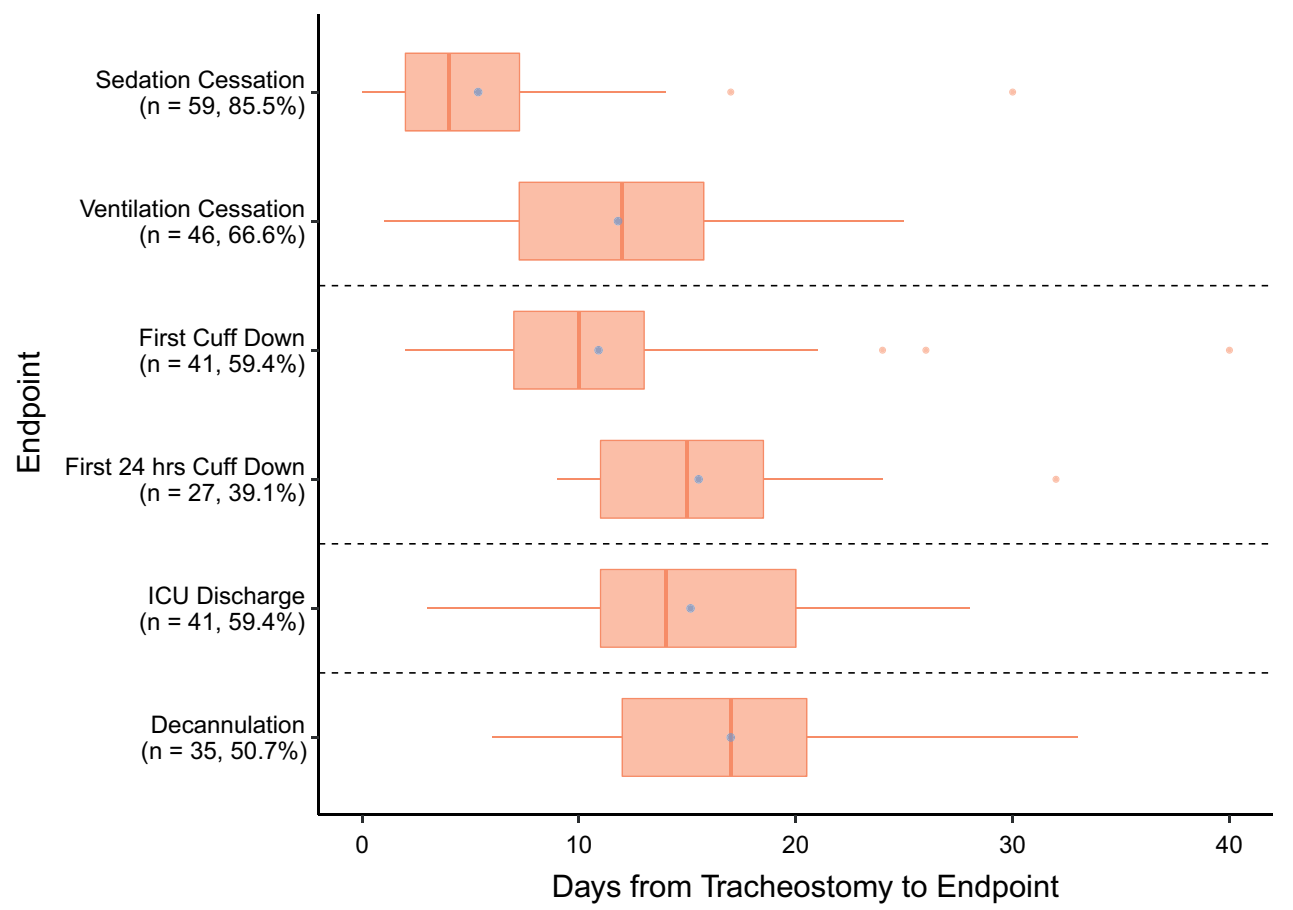

\section{Tracheostomy-related complications, weaning time-points, and outcomes}

Tracheostomy was performed a median of 16 (IQR 13-20) days after intubation. The median tracheostomy tube inner diameter was $9 \mathrm{~mm}$ for men and $8 \mathrm{~mm}$ for women (Table 1). There were seven (10.1\%) complications at the time of tube insertion: Bleeding $(3,4.3 \%)$, initial misplacement of tracheostomy tube $(2,2.9 \%)$, tracheal injury $(1,1.4 \%)$, and cuff puncture $(1,1.4 \%)$. Seven patients $(10.1 \%)$ suffered a late complication of which five were bleeding, though all were treated by adjustments to pharmacotherapy alone. One (1.4\%) patient had a cuff pilot balloon failure which required a downsize of the tracheostomy tube and one (1.4\%) patient had pneumomediastinum noted post-tracheostomy that was successfully managed.

The clinical course from tracheostomy to decannulation is represented in Fig. 1. Seventeen patients (48.6\% of decannulated patients) were decannulated on the ICU and 18 further patients $(51.4 \%)$ were decannulated following step-down to level 2 care. There was no instance of failed decannulation for respiratory reasons. One patient (1.4\%) required orotracheal re-intubation for seizures. Sixteen patients (23.2\%) were discharged from hospital a median of 23.5 days (18.75-29.50 days) after tracheostomy.

\section{Decannulation-specific outcomes}

Three patients had evidence of upper airway obstruction of which one was successfully decannulated without downsizing; one was downsized but not decannulated; and one was repatriated. Factors recognised to be associated with decannulation are shown in Table 2. In general, 10/35 $(28.6 \%)$ required a tracheostomy tube downsize prior to decannulation with all men having size $9+$ and both women having size $8+$ tubes reduced by one size. Median tracheostomy tube sizes between Group I and II were the same for men and women. Dysphonia was seen in 29 patients (73\%) at the first cuff down trial and five (14.3\%) of 35 decannulated patients required an increased $\mathrm{FiO}_{2}$ post-decannulation though most remained on room air, and none required continuous positive airway pressure or additional support.

\section{Factors associated with prolonged time to decannulation}

\section{Univariate analysis}

We compared tracheostomy duration in Group I (early) to Group II (late, see methods). This showed that patients in Group I (compared to Group II) have higher BMI and $\mathrm{PaO}_{2}: \mathrm{FiO}_{2}$ ratio (along with its constituent values) at tracheostomy. It also showed a significantly lower time from tracheostomy to first cuff down trial, significantly lower last peak cough flow prior to tracheostomy, lower $\mathrm{FiO}_{2}$ at tracheostomy, and a larger fall (i.e. improvement) in $\mathrm{FiO}_{2}$ between tracheostomy and decannulation in Group I (Tables 1 and 2). For categorical variables, there was a higher frequency of female gender and Black ethnicity in group one with a 
Table 1 Descriptive patient and critical care metrics

\begin{tabular}{|c|c|c|c|c|}
\hline Variables [number of subjects with available data] & All patients & $\begin{array}{l}\text { Group I (early) } \\
N=16\end{array}$ & $\begin{array}{l}\text { Group II (late) } \\
N=30\end{array}$ & $P$ value \\
\hline Age [69] & $55(48-61)$ & $58(28-78)$ & $56.5(22-77)$ & NS \\
\hline BMI [69] & $29.6(25.7-34.0)$ & $31.6(23.1-40.8)$ & $27.6(22.2-43.6)$ & 0.016 \\
\hline Gender (F:M) [69] & $23: 46(33.3 \%: 66.7 \%)$ & $10: 6(62.5 \%: 37.5 \%)$ & $6: 24(20 \%: 80 \%)$ & $p<0.0001$ \\
\hline \multicolumn{5}{|l|}{ Ethnicity [69] } \\
\hline White & $31(44.9 \%)$ & $7(43.8 \%)$ & $14(46.7 \%)$ & NS \\
\hline Black & $20(29.0 \%)$ & $8(50 \%)$ & $5(16.7 \%)$ & 0.017 \\
\hline Asian & $13(18.8 \%)$ & $1(6.3 \%)$ & $8(26.7 \%)$ & NS \\
\hline Mixed & $3(4.3 \%)$ & $0(0 \%)$ & $2(6.7 \%)$ & NS \\
\hline Other & $2(2.9 \%)$ & $0(0 \%)$ & $1(3.3 \%)$ & NS \\
\hline Very severe comorbidities [69] & $8(11.6 \%)$ & $3(18.8)$ & $3(10)$ & NS \\
\hline APACHE II score [59/69] & $14(11-17)$ & $12(8-22)$ & $16(6-21)$ & NS \\
\hline $\operatorname{PEEP}\left(\mathrm{cmH}_{2} \mathrm{O}\right)[69]$ & $8(6-10)$ & $7(5-10)$ & $8(5-12)$ & 0.024 \\
\hline $\mathrm{PaO}_{2}(\mathrm{mmHg})[69]$ & $7.9(6.6-8.9)$ & $9.59(4.7-12.9)$ & $9.2(6.9-13.2)$ & NS \\
\hline $\mathrm{FiO}_{2}$ (at tracheostomy) [69] & $0.40(0.30-0.45)$ & $0.3(0.25-0.45)$ & $0.4(0.21-0.55)$ & 0.021 \\
\hline $\mathrm{PaO}_{2}: \mathrm{FiO}_{2}$ ratio [69] & $202.8(160.9-243.9)$ & $234.1(77.8-387.0)$ & $193.8(114.1-345.7)$ & 0.018 \\
\hline \multicolumn{5}{|l|}{ Complications [69] } \\
\hline Peri-operative & $7(10.1 \%)$ & $4(25 \%)$ & $2(6.7 \%)$ & NS \\
\hline Post-operative & $7(10.1 \%)$ & $2(12.5 \%)$ & $2(6.7 \%))$ & NS \\
\hline Total patients affected & $13(18.8 \%)$ & $5(31.25 \%)$ & $4(13.3 \%)$ & NS \\
\hline Methylprednisolone (days) [67/69] & $11(0-15)$ & $0(0-16)$ & $11(0-26)$ & 0.018 \\
\hline Vasopressors (days) [69] & $18(26.1 \%)$ & $6(37.5 \%)$ & $10(33.3 \%)$ & NS \\
\hline RRT [69] & $25(36.2 \%)$ & $3(18.8 \%)$ & $10(33.3)$ & NS \\
\hline Anti-muscarinic (days) [63/69] & $9(14.3 \%)$ & $4(25 \%)$ & $4(13.3 \%)$ & NS \\
\hline ECMO [69] & $11(15.9 \%)$ & $1(6.3 \%)$ & $4(13.3 \%)$ & NS \\
\hline Time from intubation to tracheostomy (days) [69] & $16(13-20)$ & $14(7-24)$ & $18(6-27)$ & NS \\
\hline Proning (days) [69] & $0(0-4)$ & $0.5(0-5)$ & $0(0-11)$ & NS \\
\hline Tracheostomy tube I.D.(mm) [69] & $\begin{array}{l}\text { F: } 8(8-8) \\
\text { M: } 9(8-9)\end{array}$ & $\begin{array}{l}\text { F: } 8(7.5-8) \\
\text { M: } 9(9-9)\end{array}$ & $\begin{array}{l}\text { F: } 8(8-8) \\
\text { M: } 9(8-9)\end{array}$ & NS \\
\hline Need for tracheostomy tube downsizing [68/69] & $15(22.1 \%)$ & $2(12.5 \%)$ & $9(30 \%)$ & NS \\
\hline Tracheostomy to first cuff down (days) [65/69] & $10(7-13)$ & $8(2-10)[n=15]$ & $13(7-26)[n=29]$ & $<0.0001$ \\
\hline Last PCF before tracheostomy (L/min) [61/69] & $90(75-102)$ & $70(45-132)[n=15]$ & $101(50-180)[n=27]$ & $<0.0001$ \\
\hline First PCF after tracheostomy (L/min) (54) [54/69] & $123(100-150)$ & $128(70-200)[n=10]$ & $129(68-180)[n=23]$ & NS \\
\hline
\end{tabular}

Group I (early: decannulated $<17$ days post-tracheostomy) and Group II (late: $\geq 17$ days post-tracheostomy decannulation or not yet decannulated at $\geq 17$ day follow-up) were subjected to univariate analysis. All values are presented as the median (IQR) for continuous data and as a number (\%) for categorical data. Where data are missing from Group I and Group II column cells, the number of patients per group is indicated in square brackets. The value of APACHE II is measured on ICU admission. PEEP, $\mathrm{PaO}_{2}, \mathrm{FiO}_{2}$, and $\mathrm{PaO}_{2}:$ FiO ${ }_{2}$ ratio were measured at tracheostomy

APACHE II acute physiology and chronic health evaluation II, ECMO extracorporeal membrane oxygenation, $\mathrm{F}$ female, $\mathrm{FiO}_{2}$ fraction of inspired oxygen, I.D. inner diameter, $M$ male, $N S$ not significant, $\mathrm{PaO}_{2}$ pressure of inspired oxygen, $P C F$ peak cough flow, $P E E P$ positive end-expiratory pressure, $R R T$ renal replacement therapy

higher frequency of methylprednisolone treatment in Group II (Table 1).

\section{Multivariate regression analysis}

We assessed methylprednisolone administration as a potential confounder (to attempt to control for any disease severity differences in the treated group) and performed subgroup analysis of baseline characteristics for patients stratified by its pre-tracheostomy use. Modelling included PEEP, $\mathrm{FiO}_{2}$, last PCF before tracheostomy, $\mathrm{PaO}_{2}: \mathrm{FiO}_{2}$ ratio, gender, ethnicity, time from tracheostomy to cuff deflation, and BMI (i.e., factors from the univariate analysis where $p<0.05)$. In patients treated with corticosteroids pre-tracheostomy, BMI $(p=0.03)$ and $\mathrm{FiO}_{2}$ $(p=0.032)$ were increased and more patients were on 
Table 2 Enumeration of factors recognised to be associated with decannulation

\begin{tabular}{|c|c|c|c|}
\hline Variables & All patients & $\begin{array}{l}\text { Group I (early) } \\
N=16\end{array}$ & $\begin{array}{l}\text { Group II (late) } \\
N=30\end{array}$ \\
\hline \multicolumn{4}{|l|}{ RASS at sedation cessation [52/59] } \\
\hline Unrousable $(-5), n(\%)$ & $1(2)$ & $0(0)$ & $1(4.2)$ \\
\hline Light sedation $(-2), n(\%)$ & $3(6)$ & $0(0)$ & $0(0)$ \\
\hline Drowsy $(-1), n(\%)$ & $8(15)$ & $1(6.3)$ & $4(16.7)$ \\
\hline Alert $(0), n(\%)$ & $30(58)$ & $11(68.8)$ & $15(62.5)$ \\
\hline Restless (1), $n(\%)$ & $8(15)$ & $3(18.8)$ & $4(16.7)$ \\
\hline Agitated (2), $n(\%)$ & $1(2)$ & $0(0)$ & $0(0)$ \\
\hline Very agitated (3), $n(\%)$ & $1(2)$ & $1(6.3)$ & $0(0)$ \\
\hline \multicolumn{4}{|l|}{ Mobility at sedation cessation [42/59] } \\
\hline 1 bed only, $n(\%)$ & $15(25)$ & $6(37.5)$ & $8(26.7)$ \\
\hline 2 passive chair transfer (pat slide), $n(\%)$ & $2(3)$ & $0(0)$ & $1(3.3)$ \\
\hline 3 SOEOB, $n(\%)$ & $16(26)$ & $7(43.8)$ & $5(16.7)$ \\
\hline 4 active chair transfer, $n(\%)$ & $9(15)$ & $2(12.5)$ & $6(20)$ \\
\hline \multicolumn{4}{|l|}{ Secretions at first successful cuff down [40/41] } \\
\hline No secretions, $n(\%)$ & $1(2.5)$ & $4(22.2)$ & $1(3.7)$ \\
\hline Minimal secretions, $n(\%)$ & $19(47.5)$ & $4(22.2)$ & $14(51.9)$ \\
\hline Moderate secretions, $n(\%)$ & $18(45.0)$ & $7(38.9)$ & $6(22.2)$ \\
\hline Copious secretions, $n(\%)$ & $2(5.0)$ & $1(5.6)$ & $0(0)$ \\
\hline \multicolumn{4}{|l|}{ Secretions at first cuff down [27/41] } \\
\hline No secretions, $n(\%)$ & $4(10.0)$ & $6(40)$ & $11(52.4)$ \\
\hline Minimal secretions, $n(\%)$ & $17(42.5)$ & $4(26.7)$ & $6(28.6)$ \\
\hline Moderate secretions, $n(\%)$ & $6(15.0)$ & $4(26.7)$ & $4(19)$ \\
\hline Copious secretions, $n(\%)$ & $0(0.0)$ & $1(6.7)$ & $0(0)$ \\
\hline \multicolumn{4}{|c|}{ Upper airway patency at first cuff down trial [38/41] } \\
\hline Patent, $n(\%)$ & $35(92.0)$ & $13(92.9)$ & $19(95)$ \\
\hline Not patent, $n(\%)$ & $3(8.0)$ & $1(7.1)$ & $1(5)$ \\
\hline \multicolumn{4}{|c|}{ Swallow adequacy at first cuff down trial $[38 / 41]$} \\
\hline Adequate, number $(\%)$ & $23(61)$ & $10(71.4)$ & $10(52.6)$ \\
\hline Aspirating secretions, $n(\%)$ & $15(40)$ & $4(28.6)$ & $9(47.4)$ \\
\hline \multicolumn{4}{|l|}{ Voice at first cuff down trial [40/41] } \\
\hline Aphonic, $n(\%)$ & $3(8)$ & $2(13.3)$ & $5(23.8)$ \\
\hline Dysphonic, $n(\%)$ & $29(73)$ & $12(80)$ & $15(71.4)$ \\
\hline Normal, $n(\%)$ & $7(18)$ & $1(6.7)$ & $1(4.8)$ \\
\hline Not stated, $n(\%)$ & $1(3)$ & $0(0)$ & $0(0)$ \\
\hline \multicolumn{4}{|l|}{$\mathrm{FiO}_{2}$ peri-decannulation $[25 / 35]$} \\
\hline $\mathrm{FiO}_{2}(\text { at tracheostomy })^{\mathrm{a}}$ & $0.40(0.30-0.45)$ & $0.3(0.25-0.45)$ & $0.4(0.21-0.55)$ \\
\hline Value at decannulation, median (IQR) & $0.21(0.21-0.28)$ & $0.23(0.21-0.28)$ & $0.23(0.21-0.24)$ \\
\hline $\begin{array}{l}\text { Fall in } \mathrm{FiO}_{2} \text { between tracheostomy and } \\
\text { decannulation }\end{array}$ & $0.12(0.07-0.19)$ & $0.14(0.04-0.34)$ & $0.12(-0.1-0.22)$ \\
\hline
\end{tabular}

Decannulation-related factors are presented according to data available for relevant time-points at the point of analysis

Square brackets [number of patients with data available/number of patients that reached the relevant time point], $\mathrm{FiO}_{2}$ fraction of inspired oxygen, IQR interquartile range, $N A$ not applicable, RASS Richmond agitation-sedation scale, $S O E O B$ sitting on the edge of the bed

${ }^{\mathrm{a}} \mathrm{FiO}_{2}$ at tracheostomy is duplicated here for clarity
ECMO $(p=0.026)$. Therefore, corticosteroid-treated patient disease severity did appear increased, in line with local guidance. Therefore, methylprednisolone use was controlled for in the regression model.
This Cox regression analysis identified $\mathrm{FiO}_{2} \geq 0.4$ (HR 1.80 ; 95\% CI $0.89-3.60 ; p=0.048)$ and last PCF before tracheostomy (HR 2.27; 95\% CI 1.78-4.45; $p=0.001$ ) as independent variables associated with prolonged tracheostomy 
duration (Table 3). We did not find any known or suspected confounder of PCF (patient height, BMI, sedation, ethnicity, gender, and age [35-37]) that influenced this latter result in our cohort (e.g. Fig. 2).

\section{Discussion}

Tracheostomy insertion, care, and decannulation form a complex process requiring multidisciplinary input. Following the creation of a COVID-19 tracheostomy protocol, we sought to better understand our outcomes. Intrinsic to this understanding is an appreciation of the factors that affect the decannulation process as these inform planning and help to ensure adequate ORL-HNS, ICU, and associated healthcare professional services for future peaks [16].

Patients were decannulated in a level 2 or 3 setting (Fig. 1) and decannulation in the COVID-19 cohort is likely

Table 3 Multiple regression analysis of factors associated with prolonged decannulation

\begin{tabular}{lll}
\hline Variables & Hazard ratio (95\% CI) & $P$ value \\
\hline APACHE II score $\geq 14$ & $2.43(0.97-6.17)$ & 0.061 \\
$\mathrm{FiO}_{2} \geq 0.4$ & $1.80(0.89-3.60)$ & 0.048 \\
Last PCF before tracheostomy & $2.27(1.78-4.45)$ & 0.001 \\
\hline
\end{tabular}

We included variables that were significant in univariate analysis (Table 1): Black ethnicity, BMI, PEEP, $\mathrm{FiO}_{2}, \mathrm{PaO}_{2}: \mathrm{FiO}_{2}$ ratio, first cuff down timing, and last PCF. Starting with the most significant variable in the univariate analysis, backward stepwise log-likelihood ratio was used to determine whether inclusion of a new variable improved the fit of the Cox regression multiple model. APACHE II, $\mathrm{FiO}_{2}$, and PCF were continuous. Anti-muscarinic use was binary

APACHE II acute physiology and chronic health evaluation II, $\mathrm{FiO}_{2}$ fraction of inspired oxygen, $P C F$ peak cough flow

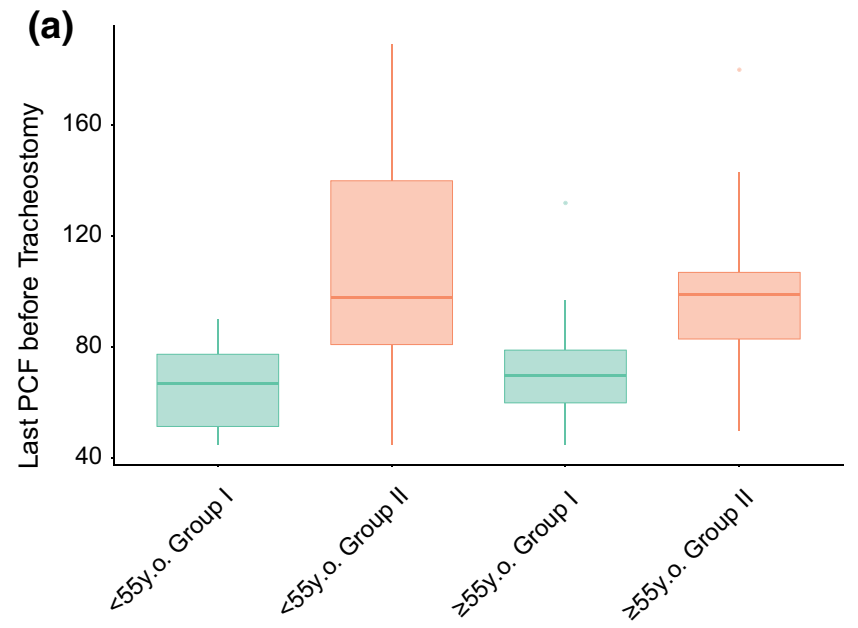

to take longer than in comparable viral pneumonia patients as cuff deflation was delayed until after MV cessation to reduce aerosol generation. Our patients appear similar to critically unwell COVID-19 patients in the UK in terms of age and gender. However, their BMI is higher. Furthermore, three times the percentage of patients in our population are of Black ethnicity compared to national figures [31]. In the subgroup analysis, more patients in the early decannulation group (Group I) were female (Table 1) and this may be due to female patients generally being less severely affected by COVID-19 [38]. The reason for a higher median BMI in this group is less clear.

The increased number of patients of Black and Asian ethnicity is in keeping with UK national trends for these ethnicities to be over-represented in COVID-19 cohorts despite geographical adjustments [31, 39]. In our experience, this may be at least partly in keeping with the relatively high representation of these groups in the UK healthcare worker population [40].

\section{Factors affecting tracheostomy decannulation}

Our findings showed that the use of methylprednisolone was more common in Group II (late) (Table 1). This treatment was given for immunomodulation of hyperinflammatory (severe) COVID-19 according to our local protocols though the indications and effect of steroid treatment in this context remains to be proven [24, 25]. In an attempt to identify more tracheostomy-related factors that may be associated with prolonged decannulation, its usage was controlled for in our multivariate analysis.

Our local guideline indicates a $\mathrm{FiO}_{2}$ of 0.4 with PEEP of $8 \mathrm{cmH}_{2} \mathrm{O}$ prior to tracheostomy and we maintain good adherence to these parameters (Table 1). Our analysis identified

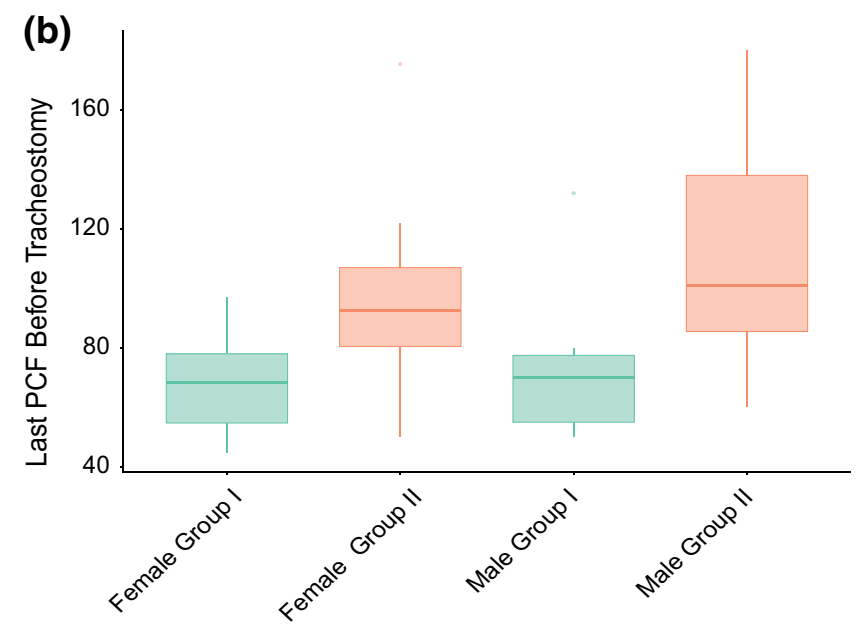

Fig. 2 Illustrative boxplots to peak cough flow confounding factors. a Age compared to last PCF before tracheostomy by decannulation group; b gender compared to last PCF before tracheostomy by decannulation group. $F$ female, $M$ male, $P C F$ peak cough flow, y.o. years old 
PEEP, $\mathrm{FiO}_{2}, \mathrm{PaO}_{2}: \mathrm{FiO}_{2}$ ratio at tracheostomy, and the fall in $\mathrm{FiO}_{2}$ from tracheostomy to decannulation as being worse in patients in Group II (Tables 1 and 2). This informed the Cox regression model from which a higher $\mathrm{FiO}_{2}$ at tracheostomy emerged as an independent variable associated with prolonged tracheostomy duration. This finding is uncontroversial as we would expect patients with worse respiratory function-as marked by a higher oxygen requirement, even within the constraints of our selected population-to take longer to be decannulated.

Of the remaining factors fed forward to the multivariate regression, the last PCF (a measure of cough strength) prior to tracheostomy formation was a significant factor associated with delayed decannulation. We hypothesised that patients with a stronger PCF prior to tracheostomy may have a shorter tracheostomy duration as a strong cough typically denotes less ventilator-acquired weakness [20-22], and the literature supports this [41]. In fact, the opposite was found. We have not found any evidence of confounding by factors known to modulate PCF (e.g., Fig. 2) [35-37]. This leaves the interesting possibility that patients with worse COVID19 have more airway hyper-reactivity and that a similar stimulus may provoke a higher PCF in these patients due to greater airway inflammation, though this remains to be proven.

PCF following tracheostomy was not found to be correlated with tracheostomy duration. The reasons for this are likely multifactorial. Post-tracheostomy PCF measurements are generally measured on command rather than in response to standardised saline instillation or a spontaneous cough. Furthermore, other changes in physiology once a tracheostomy is inserted-such as reduced airway resistance and the ability to close the glottis-likely further confound this measurement.

\section{Laryngotracheal sequelae of COVID-19 airway management}

Patients with $>7$ days of orotracheal intubation (68/69, $98.6 \%$ in our cohort) are known to be at increased risk of laryngotracheal complications and there has been speculation that COVID-19 is associated with laryngeal oedema [42]. Despite this, there were no failed decannulations for respiratory reasons amongst our 35 decannulated patients and only a small number of patients $(3 / 41,7.3 \%)$ had upper airway obstruction signs on their first cuff down trial. Furthermore, despite favouring tracheostomy tubes of larger inner diameter, the majority of decannulated patients $(25 / 35$, $71.4 \%$ ) did not require downsizing prior to decannulation. These findings suggest that concerns over laryngeal oedema may be unfounded or resolved by the time of tracheostomy weaning.
Finally, a series of 98 cases where a novel technique of passing a bronchoscope alongside an endotracheal tube was employed in percutaneous tracheostomy for COVID-19 showed that only two patients (both on ECMO) had significant upper airway oedema [29]. This reassuring finding will not necessarily carry forward to long-term speech, swallowing, and breathing outcomes given the duration for which COVID-19 patients have had endotracheal and tracheostomy tubes in situ (Fig. 1) [9,43]. Therefore, the high rate of dysphonia that we identified at the first cuff down trial (Table 2) requires further follow-up to determine whether we will see a significant laryngological rehabilitation burden.

\section{Comparison with existing background literature regarding decannulation}

Our study represents a relatively large report on the topic of decannulation in respiratory failure due to viral pneumonia, though limited in duration [21]. As mentioned, we are not aware of any respiratory-related failed tracheostomy decannulations to date- though one patient failed decannulation due to seizures and we are aware of one other patient with COVID-19 who underwent tracheostomy for a neurological indication and failed decannulation due to laryngeal dysfunction. Our outcomes may be due to judicious ICU management of factors such as secretions (Table 2) with highly specialist physiotherapy and SLT input facilitating tailored weaning plans. Our intraoperative complication rate is comparable to the existing literature [44].

\section{Comparison of our population to existing COVID-19 studies}

This study represents the most detailed report of which we are aware regarding tracheostomy decannulation in COVID19 [26-30]. Compared to another report on tracheostomy outcomes in COVID-19 in a large and ethnically diverse city (New York, US), our male-to-female ratio of 2:1 is lower than their 3:1 ratio. Our populations are broadly comparable — in terms of age and BMI - to other reports [28-31]. We tend to perform tracheostomy 5 days later (mean day $16.9 \mathrm{vs}$ 10.6 days), though the standard deviations of tracheostomy timing overlap between our groups [29]. The four patients excluded from the current study due to death from COVID19 represent $5.1 \%$ of all tracheostomies performed and this is also comparable [29]. There were no tracheostomy-related deaths in our cohort.

Due to the topical nature of this study, many patients are still completing their care. Therefore, a variable number of patients have complete outcomes and the overall sample, though comparable with respiratory failure subsets of existing studies, is small [21,22]. This may have contributed to the imbalanced size of our subgroups which, combined with 
the multiple comparisons made, make it difficult to draw any firm conclusions from the univariate analysis. Cox regression, on the other hand, is designed to control for these challenges. Following correction for disease severity, the number of variables that entered this analysis was limited to ensure that any significant results were adequately robust. Unfortunately, it was not possible to gain patient input on factors that would have been important to them given the study timing.

Despite a design incorporating many factors of the therapist-led decannulation process and clinician experience suggesting that post-tracheostomy factors such as neurological status and myopathy should significantly affect tracheostomy duration, this is not supported by the above evidence. A larger sample size with further disease severity controls would be needed to generate adequately large subgroups to power further analysis.

In patients undergoing tracheostomy for primary respiratory indications following COVID-19, multivariate analysis identified that $\mathrm{FiO}_{2}$ at tracheostomy was associated with time to decannulation. A high peak cough flow prior to tracheostomy formation is a novel finding associated with longer tracheostomy duration that appears worthy of further investigation, whereas recognised factors implicated in the decannulation process did not correlate with tracheostomy duration. It is our hope that an understanding of the timecourse of COVID-19 tracheostomy provided herein may allow better planning of care provision for future pandemic peaks.

Acknowledgements The authors would like to thank Christina Iezzi for her help in preparing outcome measures for this study.

\section{Compliance with ethical standards}

Conflict of interest The authors declare that they have no conflict of interest.

\section{References}

1. Wu Z, McGoogan JM (2020) Characteristics of and important lessons from the coronavirus disease 2019 (COVID-19) outbreak in china: summary of a report of 72314 cases from the chinese center for disease control and prevention. JAMA-J Am Med Assoc 323:1239-1242. https://doi.org/10.1001/jama.2020.2648

2. Huang C, Wang Y, Li X, Ren L, Zhao J, Hu Y et al (2020) Clinical features of patients infected with 2019 novel coronavirus in Wuhan, China. Lancet 395:497-506. https://doi.org/10.1016/ S0140-6736(20)30183-5

3. Gold JAW, Wong KK, Szablewski CM, Patel PR, Rossow J, Silva J et al (2020) Characteristics and clinical outcomes of adult patients hospitalized with COVID-19-Georgia, March 2020. Morb Mortal Wkly Rep 69:1-6

4. Carenzo L, Costantini E, Greco M, Barra FL, Rendiniello V, Mainetti M et al (2020) Hospital surge capacity in a tertiary emergency referral centre during the COVID-19 outbreak in Italy. Anaesthesia 1174:1-7. https://doi.org/10.1111/anae.15072
5. Litton E, Bucci T, Chavan S, Ho YY, Holley A, Howard G et al (2020) Surge capacity of intensive care units in case of acute increase in demand caused by COVID-19 in Australia. Med J Aust. https://doi.org/10.5694/mja2.50596

6. Shoukat A, Wells CR, Langley JM, Singer BH, Galvani AP (2020) Projecting demand for critical care beds during COVID19 outbreaks in Canada. CMAJ. https://doi.org/10.1503/ cmaj. 200457

7. Anandaciva S (2020) Critical care services in the English NHS. In: King's Fund. Critical care services in the English NHS. Accessed 9 May 2020

8. Adly A, Youssef TA, El-Begermy MM, Younis HM (2018) Timing of tracheostomy in patients with prolonged endotracheal intubation: a systematic review. Eur Arch Oto-Rhino-Laryngol 275:679-690. https://doi.org/10.1007/s00405-017-4838-7

9. Curry SD, Rowan PJ (2020) Laryngotracheal stenosis in early vs late tracheostomy: a systematic review. Otolaryngol-Head Neck Surg (US) 162:160-167. https://doi.org/10.1177/01945 99819889690

10. Wang R, Pan C, Wang X, Xu F, Jiang S, Li M (2019) The impact of tracheotomy timing in critically ill patients undergoing mechanical ventilation: a meta-analysis of randomized controlled clinical trials with trial sequential analysis. Hear Lung 48:46-54. https:// doi.org/10.1016/j.hrtlng.2018.09.005

11. Sommer DD, Engels PT, Usaf C, Khalili S, Corsten M, Tewfik MA et al (2020) Recommendations from the CSO-HNS taskforce on performance of tracheotomy during the COVID-19 pandemic. J Otolaryngol Head Neck Surg 49:23. https://doi.org/10.1186/s4046 3-020-00414-9

12. Mcgrath BA, Brenner MJ, Warrillow SJ, Pandian V, Arora A, Cameron TS et al (2020) Health-care development tracheostomy in the COVID-19 era: global and multidisciplinary guidance. Anaesthesia 2600:1-8. https://doi.org/10.1016/S2213 $-2600(20) 30230-7$

13. Lin WC, Chen CW, Der Wang J, Tsai LM (2015) Is tracheostomy a better choice than translaryngeal intubation for critically ill patients requiring mechanical ventilation for more than 14 days? A comparison of short-term outcomes. BMC Anesthesiol 15:1-8. https://doi.org/10.1186/s12871-015-0159-9

14. Parker NP, Schiff BA, Fritz MA, Rapoport SK, Schild S, Altman KW et al (2020) Tracheotomy recommendations during the COVID-19 pandemic. Am Acad Otolaryngol-Head Neck Surg. https://www.entnet.org/content/tracheotomy-recommendations -during-covid-19-pandemic. Accessed 11 May 2020

15. Schultz $P$, Morvan J-B, Fakhry N, Morinière S, Vergez S, Lacroix $C$ et al (2020) French consensus regarding precautions during tracheostomy and post-tracheostomy care in the context of COVID19 pandemic. Eur Ann Otorhinolaryngol Head Neck Dis. https:// doi.org/10.1016/j.anorl.2020.04.006

16. Takhar A, Walker A, Tricklebank S, Wyncoll D, Hart N, Jacob $T$ et al (2020) Recommendation of a practical guideline for safe tracheostomy during the COVID-19 pandemic. Eur Arch Otorhinolaryngol. https://doi.org/10.1007/s00405-020-05993-x

17. NCEPOD (2014) On the right trach? J Anaesth Pract 24:158-159. https://www.ncepod.org.uk/2014report1/downloads/OnTheRight Trach_FullReport.pdf. Accessed 4 May 2020

18. BLA (2020) Tracheostomy guideline Covid-19 tracheostomy guideline. ENT UK, pp 1-6. https://www.britishlaryngologica 1.org/sites/default/files/BLA\%20Tracheostomy\%20guideline\%20 -BLA\%20April\%202020\%20FINAL.pdf. Accessed 14 May 2020

19. RCSLT (2020) RCSLT GUIDANCE speech and language therapist-led endoscopic procedures in the COVID-19 pandemic. https://www.rcslt.org/-/media/docs/Covid/RCSLT-COVID -19-SLT-led-endoscopic-procedure-guidance_FINAL-(2). $\mathrm{PDF} ? \mathrm{la}=$ en $\&$ hash $=8101575091 \mathrm{FE} 8 \mathrm{~F} 1 \mathrm{ABA} 41 \mathrm{~B} 4 \mathrm{~B} 472387 \mathrm{D}$ AFB023A39D. Accessed 9 May 2020 
20. Kutsukutsa J, Kuupiel D, Monori-Kiss A, Del Rey-Puech P, Mashamba-Thompson TP (2019) Tracheostomy decannulation methods and procedures for assessing readiness for decannulation in adults: a systematic scoping review. Int J Evid Based Healthc 17:74-91. https://doi.org/10.1097/XEB.0000000000000166

21. Singh RK, Saran S, Baronia AK (2017) The practice of tracheostomy decannulation-a systematic review. J Intensive Care. https ://doi.org/10.1186/s40560-017-0234-z

22. Santus P, Gramegna A, Radovanovic D, Raccanelli R, Valenti V, Rabbiosi D et al (2014) A systematic review on tracheostomy decannulation: a proposal of a quantitative semiquantitative clinical score. BMC Pulm Med 14:1-8. https://doi. org/10.1186/1471-2466-14-201

23. Alhazzani W, Møller MH, Arabi YM, Loeb M, Gong MN, Fan E et al (2020) Surviving Sepsis Campaign: guidelines on the management of critically ill adults with coronavirus disease 2019 (COVID-19). Springer, Berlin

24. Ye Q, Wang B, Mao J (2020) The pathogenesis and treatment of the 'Cytokine Storm'" in COVID-19'. J Infect. https://doi. org/10.1016/j.jinf.2020.03.037

25. Russell CD, Millar JE, Baillie JK (2020) Clinical evidence does not support corticosteroid treatment for 2019-nCoV lung injury. Lancet 395:473-475. https://doi.org/10.1016/S0140 $-6736(20) 30317-2$

26. Stubington TJ, Hospital RD, Mansuri MS (2020) Tracheotomy in COVID-19 patients: optimizing patient selection and identifying prognostic indicators. Authorea. https://doi.org/10.22541/ au.158888293.33092171 (pre-print)

27. Turri-Zanoni M, Battaglia P, Czaczkes C, Pelosi P, Castelnuovo P, Cabrini L (2020) Elective tracheostomy during mechanical ventilation in patients affected by COVID-19: preliminary case series from Lombardy, Italy. Otolaryngol Head Neck Surg. https://doi. org/10.1177/0194599820928963

28. Takhar A, Tornari C, Amin N, Wyncoll D, Arora A, Ahmad I et al (2020) Percutaneous tracheostomy in COVID-19 pneumonitis patients requiring prolonged mechanical ventilation : Initial experience in 51 patients and preliminary outcomes. Authorea. https://doi.org/10.22541/au.158801954.47538762/v2 (pre-print)

29. Angel L, Kon ZN, Chang SH, Rafeq S, Shekar SP, Mitzman B et al (2020) Novel percutaneous tracheostomy for critically ill patients with COVID-19. Ann Thorac Surg. https://doi.org/10.1016/j.athor acsur.2020.04.010

30. Broderick D, Kyzas P, Baldwin AJ, Graham RM, Duncan T, Chaintoutis C et al (2020) Surgical tracheostomies in COVID-19 patients: a multidisciplinary approach and lessons learned. Oral Oncol. https://doi.org/10.1016/j.oraloncology.2020.104767

31. ICNARC (2020) Report on COVID-19 in critical care. Intensive Care Natl Audit Res Cent, 1-24. https://www.icnarc.org/OurAudit/Audits/Cmp/Reports

32. Rovira A, Dawson D, Walker A, Tornari C, Dinham A, Foden $\mathrm{N}$ et al (2020) Tracheostomy care and decannulation during the COVID-19 pandemic. Eur Arch Oto-Rhino-Laryngol, A multidisciplinary clinical practice guideline. https://doi.org/10.1007/ s00405-020-06126-0

33. Mehta P, McAuley DF, Brown M, Sanchez E, Tattersall RS, Manson JJ (2020) COVID-19: consider cytokine storm syndromes and immunosuppression. Lancet. 395(10229):1033-1034. https://doi. org/10.1016/S0140-6736(20)30629-0

34. Mokhlesi B, Tulaimat A, Gluckman TJ, Wang Y, Evans AT, Corbridge TC (2007) Predicting extubation failure after successful completion of a spontaneous breathing trial. Respir Care 52:1710-1717

35. Cardoso FEF, De Abreu LC, Raimundo RD, Faustino NANM, Araújo SF, Valenti VE et al (2012) Evaluation of peak cough flow in Brazilian healthy adults. Int Arch Med 5:2-5. https://doi. org/10.1186/1755-7682-5-25

36. Quanjer PH, Stanojevic S, Cole TJ, Baur X, Hall GL, Culver BH et al (2012) Multi-ethnic reference values for spirometry for the 3-95-yr age range: the global lung function 2012 equations. Eur Respir J 40:1324-1343. https://doi.org/10.1183/09031936.00080 312

37. Shahane N, Edward K, Hospital M, Jiandani MP, Edward K, Hospital M (2018) Correlation of peak cough flow rate with peak expiratory flow rate in patients with chronic respiratory diseases correlation of peak cough flow rate with peak expiratory flow rate in patients with chronic respiratory diseases. NJIRM 9:21-25

38. Richardson S, Hirsch JS, Narasimhan M, Crawford JM, McGinn T, Davidson KW et al (2020) Presenting characteristics, comorbidities, and outcomes among 5700 patients hospitalized with COVID-19 in the New York City area. JAMA 10022:1-8. https:// doi.org/10.1001/jama.2020.6775

39. UK Government: Regional Ethnic Diversity. https://www.ethni city-facts-figures.service.gov.uk/uk-population-by-ethnicity/ national-and-regional-populations/regional-ethnic-diversity/lates t\#data-sources. Accessed 11 May 2020

40. Platt L, Warwick R (2020) Are some ethnic groups more vulnerable to COVID-19 than others? Inst Fisc Stud. https://www.ifs. org.uk/inequality/chapter/are-some-ethnic-groups-more-vulne rable-to-covid-19-than-others/. Accessed 11 May 2020

41. Winck JC, LeBlanc C, Soto JL, Plano F (2015) The value of cough peak flow measurements in the assessment of extubation or decannulation readiness. Rev Port Pneumol 21:94-98. https:// doi.org/10.1016/j.rppnen.2014.12.002

42. McGrath BA, Wallace S, Goswamy J (2020) Laryngeal oedema associated with COVID -19 complicating airway management. Anaesthesia. https://doi.org/10.1111/anae.15092

43. de Oliveira ACM, de Friche AA, Salomão MS, Bougo GC, Vicente LLC (2018) Predictive factors for oropharyngeal dysphagia after prolonged orotracheal intubation. Braz J Otorhinolaryngol 84:722-728. https://doi.org/10.1016/j.bjorl.2017.08.010

44. Young D, Harrison DA, Cuthbertson BH, Rowan K (2013) Effect of early vs late tracheostomy. JAMA 309:2121-2129. https://doi. org/10.1001/jama.2013.5154

Publisher's Note Springer Nature remains neutral with regard to jurisdictional claims in published maps and institutional affiliations. 